\title{
ALGUNAS COMUNIDADES RUPÍCOLAS EN EL LITORAL DE MÁLAGA Y GRANADA
}

\author{
B. Díez Garretas*
}

\section{RESUMEN}

Se realiza un comentario crítico de las comunidades rupícolas litorales de las provincias de Málaga y Granada, describiendo como nuevas, la asociación CrithmoLimonietum auriculae-ursifolii y la subas. limonietosum gummiferae de la LimonioLycietum intricati Esteve 1972.

\section{SUMMARY}

A critical study on the coastal rock communities of the Málaga and Granada provinces is reported here. For the first time the communities Crithmo-Limonietum auriculae-ursifolii and the subas, limonietosum gummiferae (Limonio-Lycietum intricati Esteve 1972) are found in this area.

El litoral de la provincia corológica Bética (RIVAS MARTínez, 1973) se caracteriza por presentar, playas fuertemente nitrófilas, originadas sobre todo por relleno aluvial, donde se localizan comunidades de Euphorbion peplis (Sporobolo-Centaureetum seridis, Sporobolo-Centaureetum sphaerocephalae), algunos puntos con desarrollo dunar, cuyas comunidades ya fueron estudiadas por nosotros (Díez, B., Hernández, A. M. \& Asensi, A., 1975) y (Diez Garretas, B., Asensi, A. \& Esteve, F., 1977) y en la parte oriental gran profusión de roquedos y acantilados marinos, como los comprendidos entre Castell de Ferro y Calahonda, ambos en la provincia de Granada, constituidos por calizas y dolomías del Triásico y los que van desde Salobreña (Granada) a Nerja (Málaga) formados por micaesquistos y cuarcitas del Permotrias. En estas formaciones, nos ha sido posible reconocer las comunidades que a continuación describimos.

Crithmo-Limonietum auriculae-ursifolii nova. Se presenta en los roquedos y acantilados desde Nerja hasta Torremolinos en Málaga, es una comu-

* Departamento de Botánica. Facultad de Ciencias de la Universidad de Málaga. 
nidad pobre en especies, básicamente constituida por Crithmum maritimum, Asteriscus maritimus y Limonium auriculae-ursifolium. En los rellanos rocosos más alejados de la influencia directa del mar, entran a formar parte de la comunidad otras especies como, Frankenia laevis y Mesembrianthemum modiflorum que podrían representar una variante nitrófila.

Damos como inventario tipo de la asociación (syntypus) el número 5 de la tabla que se acompaña.

Limonio-Lycietum intricati Esteve 1972 limonietosum gummiferae nova. Esta asociación ya descrita (ESTEVE, 1972), lleva como taxones característicos Lycium intricatum y Limonium cymuliferum, este último en la descripción original de la comunidad se interpreta como una buena diferencial. Nosotros hemos encontrado sobre los roquedos litorales en el sector más oriental de la provincia de Granada, una comunidad similar a la descrita por ESTLVE en la que Limonium gummiferum sustituye a Limonium cymuliferum, por ello creemos que puede describirse una subasociación de nombre limonietosum gummiferae que representaría una etapa más meridional de la comunidad ya descrita. Se elige como syntypus el inventario n. ${ }^{\circ} 3$.

Limonio-Lycietum intricati Esteve 1972 subas. limonietosum gummiferae nova.

$\begin{array}{lrrrrrr}\text { N. }{ }^{\circ} \text { inventario } & 1 & 2 & 3 & 4 & 5 & 6 \\ \text { Inclinación (\%) } & 60 & 90 & 45 & 45 & 20 & 40 \\ \text { Orientación } & \mathrm{E} & \mathrm{W} & \mathrm{S} & \mathrm{SE} & \mathrm{SE} & \mathrm{SE} \\ \text { Área }\left(\mathrm{m}^{2}\right) & 5 & 6 & 6 & 4 & 8 & 12 \\ \text { Altitud (m.s.m.) } & 4 & 10 & 10 & 6 & 7 & 20 \\ \text { Cobertura (\%) } & 50 & 20 & 60 & 15 & 40 & 50\end{array}$

Características de asociación y unidades superiores: (Crithmo-Limonion, Critmo-Limonietalia, Critmo-Linonietea):

$\begin{array}{lcccccc}\text { Asteriscus maritimus } & 1.2 & 1.1 & 2.2 & 1.2 & 1.2 & 1.2 \\ \text { Lycium intricatum } & +.2 & + & 2.3 & . & . & + \\ \text { Crithmum maritimum } & + & . & . & . & . & .\end{array}$

Diferencial de la subas. limonietosum gummiferae:
Limonium gummiferum
2.2
2.1
3.4
$1.2 \quad 3.3$
2.3

Compañeras :

Sonchus tenerrimus $\quad 1.1+{ }_{+}+++$

Lotus creticus

Además: Reichardia tingitana en 3; Atriplex glauca en 6 (2.2).

Localidades: 1, 2 y 3 Roquedos próximos a La Rábita (Granada). 4, 5 y 6 Playas de la Rijana, Castell de Ferro (Granada). 


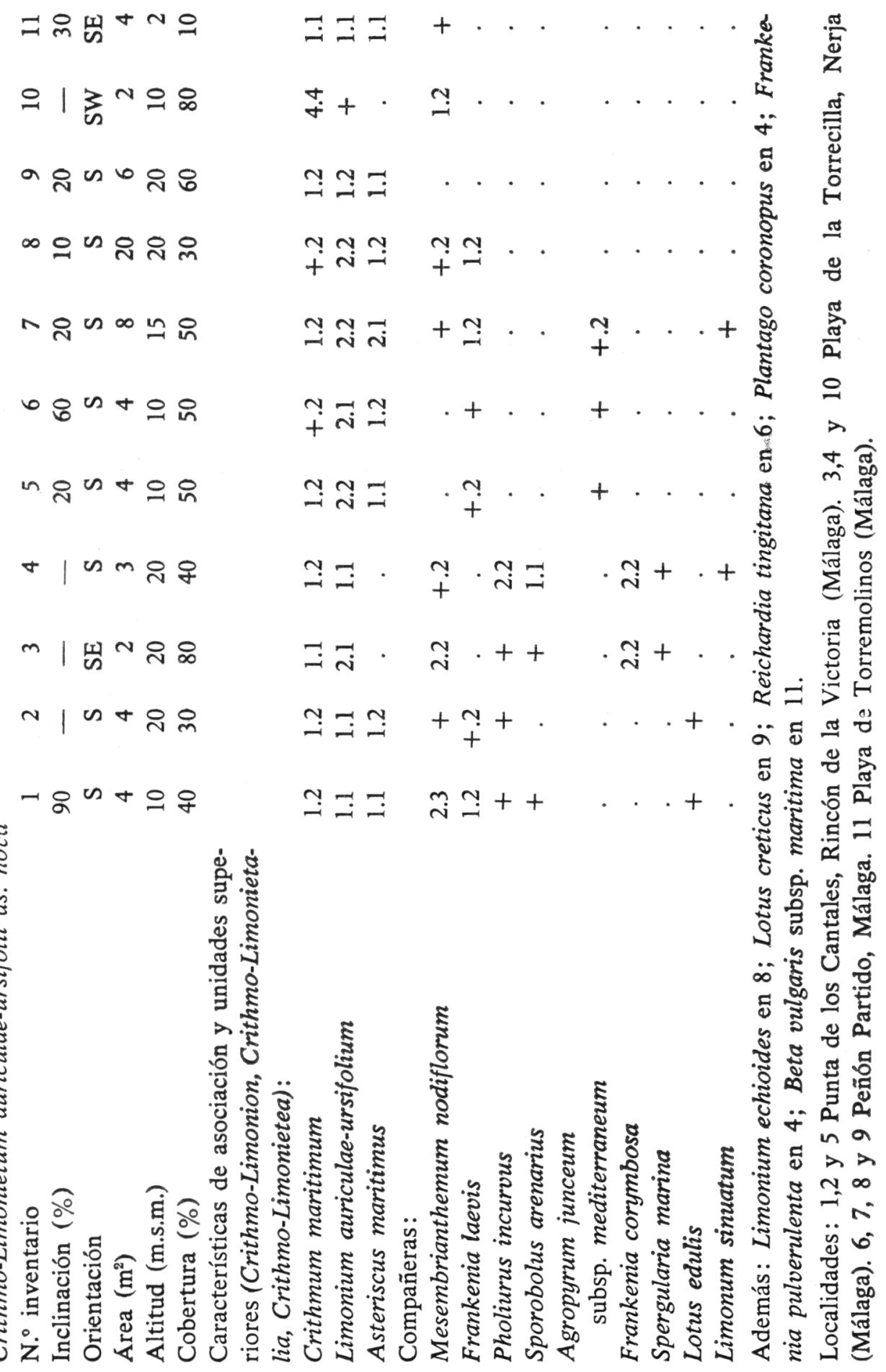




\section{BIBLIOGRAFIA}

Bolos, O. 1967. Comunidades vegetales de las comarcas próximas al litoral situadas entre los ríos Llobregat y Segura. Mem. Real Acad. Cienc. y Artes, 38(1): 3-280. Barcelona.

Díez GaRretas, B. 1977. Flora y vegetación del litoral marino de las provincias de Málaga y Granada. Tesis doctoral inédita. Fac. de Ciencias. Málaga.

Díez Garretas, B., Hernández, A. M. \& Asensi, A. 1975. Estructura de algunas comunidades vegetales de dunas en el litoral de Marbella (Málaga). Act. Bot. Malacitana, 1:69-80. Málaga.

Dfez Garretas, B., Asensi, A. \& Esteve, F. 1977. Pastizales terofíticos de playas y dunas en el sur de la Península Ibérica. Colloques phytosociologiques, 6 , en prensa. Lille.

Esteve Chueca, F. 1972. Vegetación y Flora de las regiones central y meridional de la provincia de Murcia. Centro Edaf. y Biol. aplicada del Segura. Murcia.

Pignatti, S. 1962. Note sulla sistematica delle specie iberiche di Limonium. Collect. Botanica, 6(1,2):1-39. Barcelona.

Rivas Martínez, S. 1973. Avance para una síntesis corológica de la Península Ibérica, Baleares y Canarias. Anal. Inst. Bot. A. J. Cavanilles, 30:69-89. Madrid.

(Recibido el 15 de septiembre de 1977) 